\title{
Development of Equipment for the Study of Erosion Caused by Water-Solid Mixture.
}

\author{
Thais M. T. Azevedo*, José G. Dalfré Filho, Renan de L. Branco, Gianandrea V. Messa, Stefano Malavasi.
}

\begin{abstract}
Due to the change in the occupation of hydrographic basins, more solid materials can be released to the water courses, which increases the susceptibility to erosion by impact of hydraulic surfaces. In areas where there is an intense carrying of solid material by water, the concept of the structure must take into account the possibility of erosion being severe. It is essential, then, to determine the composition of the concrete used in new projects or in the repair of existing problems. Tests must be performed in an equipment that simulates the erosive phenomenon, in a realistic perspective. This project consists of an experimental research, developing and optimizing an equipment that simulates the erosion of concrete and mortar by water-solid mixture.
\end{abstract}

\section{Key words:}

Erosion, hydraulic surfaces, experiment.

\section{Introduction}

An important problem, which requires constant investigation, is the prediction of erosion quantification. Erosion is one of the major problems in hydraulic systems where there is transport of fluids and solid particles. In order to equate erosion, three components must be taken into account: the solid surface, the solid particles that remove material from the surface and the fluid that carries the solid particles. However, many variables are associated with each component and, consequently, cannot be easily equated. The objective of this work is to present the final version of an equipment for erosion of concrete by watersolid mixture.

\section{Results and Discussion}

The tests performed in this project were divided into two stages: the first, using concrete samples and the second, mortar samples. Both of them were performed using the Malavasi (2013) equipment, shown in Image 1. Erosion was characterized by the sample's loss of mass over time. The concrete and mortar samples were rehearsed over predetermined times, which were different for each material due to their different resistance.

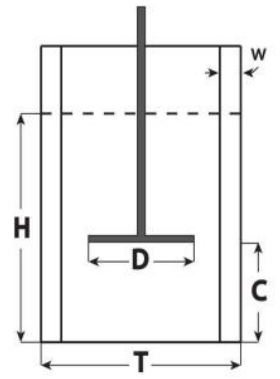

Image 1. Equipment layout.

Besides that, the tests of the first stage were performed shifting shovel's distance to the sample based on shovel's diameter (D) between 5.60 (0.33D) and 10 (0.59D) $\mathrm{cm}$ for each analyzed sample. Otherwise, the mortar samples were performed using the same tank parameters for all of them. According to Malavasi et. al. (2013) and his mathematical model, a distance of $0.33 \mathrm{D}$ would cause more intense erosion than a $0.59 \mathrm{D}$ distance, due to the impact angle and speed. The results of tests with concrete samples are shown in Image 2.

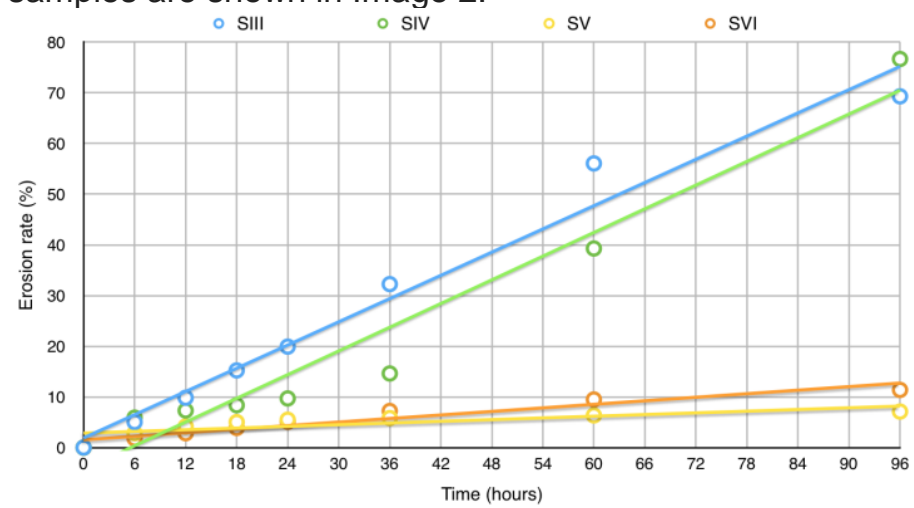

Image 2. Erosion rate over time of concrete samples

Mortar samples tests results presented an erosion rate more intense than concrete samples over time, which is explained by the resistance of mortar in comparison to concrete and the composition of the material.

\section{Conclusions}

By the end of the tests with concrete, the results confirmed Malavasi's mathematical model. The blue and orange lines are representative of $0.33 \mathrm{D}$ distance, which caused more erosion.

Mortar tests, on the other hand, serve as basis for future studies comparing the impact of different sizes of aggregate in erosion.

\section{Acknowledgement}

We would like to thank PIBIC and CNPQ for the incentive and sponsorship to the research. Withal, thanks to LHMF's laboratory technicians Marcelo Balbino and Jefferson C. Rocha for all the help, support and attendance during the tests.

Dalfré Filho, J.G.; Genovez, A.I.B.; Paulon, W.A Ingeniería Estructural. 2000, 8(20), pp. 18-22.

Malavasi, S.; Gianandrea, V.M.; Righini, A.; Dalfré Filho, J.G. In: XX Simpósio Brasileiro de Recursos Hídricos, ABRH, Bento Gonçalves. 2013.

DOI: 10.19146/pibic-2017-79109 